\title{
Management of the Pre Pubertal Girls with Labial Adhesions
}

\author{
Paul BJ ${ }^{1}$, Das $C R^{2}$
}

\begin{abstract}
:
Back ground: Pre pubertal labial adhesion is an important pediatric gynecological problem. Parents panic about this condition as absent vagina, which is rather very easy to handle in a very simple, rapid, surgical management. Objective: the purpose of this study was to evaluate the efficacy of surgical treatment on prepubertal girls with labial adhesions. Methods: A period of 3 years from May 2011 to May 2014 was taken to conduct a study about this condition on prepubertal girls. The place of study was Nepalgunj Medical College, Kohalpur, Banke, Nepal. All patients underwent either outpatient surgical treatment or in operation theatre under short anesthesia, those who were either frightened or non cooperative. They were placed in gynecological (dorsal) position. A thin stainless steel lubricated probe or 1-2 mm. size, Hegar dilator was used to separate the labia minora by firm pressure. Result: All patients were successfully treated and at present they are being followed for recurrence. Conclusion: This benign disorder can be treated by any gynecologist as an office procedure.
\end{abstract}

Key words: Labial adhesion, labial agglutination, pre pubertal girls

\section{INTRODUCTION}

prepubertal labial adhesion is an important pediatric gynaecological problem. This is often mistaken with congenital atresia of vagina ${ }^{1}$. Labial agglutination is a condition leading to adhesion of labia minora in the midline. Prior to adhesion there is denudation and thinning of labia ${ }^{2}$. The agglutinations usually begins posteriorly and extends upwards towards the clitoris. Labial adhesion occurs in one to thirty eight percent of female children aged from 13 months to 6 years $^{3}$. Labial agglutination results in a partial or complete adhesion of labia minora. the labia are normally covered with this non estrogenic epithelium. They have been exposed to inflammation and subjected to maceration commonly secondary to vulvo vaginitis

The denuded surface then exude a fibrinous, serosal product causing the labia to adhere or stick to each other. Superficial epithelialisation bridges the adhesions producing an apparent mid line raphe. This process commences at the fourchette and progresses ventrally to varying degree. Therefore the appearance of the raphe is a characteristics livid line extending vertically down the centre of the membranes distinguish agglutination from the less commonly encountered

\section{Dr. B. J. Paul}

2. Prof. C. R. Das

Address for correspondence:

Dr. B. J. Paul

Department of Obst. \& Gynae.

Nepalgunj Medical College Teaching Hospital

Kohalpur, Banke, Nepal

Email: bhaskarjpaul@yahoo.co.in imperforate hymen or vaginal atresia. In doing so it will favor persistence of vaginitis and rarely can cause obstruction of the urethra. The adhesive process with occasionally commence near the clitoris forming so called prepucial adhesion.

\section{MATERIALS AND METHODS}

The period of study was between May 2008 to May 2012. All prepubertal girls coming to gynecological outpatient department with the complaint of labial adhesions were included in this study. All patients underwent either outpatient surgical treatment or in operation theatre under short anesthesia who were either frightened or non cooperative. A lubricate stainless steel probe or $2 \mathrm{~mm}$ size Hegar dilator was used to separate labia minora with firm pressure and Clotrimazole vaginal cream was applied.

\section{RESULTS}

All the cases, adhesions were separated by quick firm pressure with lubricated probe. Short IM anesthesia (ketamin) was used in such situation where the child was non cooperative. We have tried to separate the labia minora without anesthesia by lubricating the probe or Hegar dilator (1-2 $\mathrm{mm}$ ) with xylocaine jelly without much difficulty.

\section{DISCUSSION}

Labial adhesion is a benign genital disorder in girls. Labial fusion may be congenitally acquired, some times happens due to poor hygiene. In this part of the world poor hygiene and cold climate is one of the common cause. The diagnosis can be established by examining the genitalia with a probe and with assistance of the concerned parent (mother). In the circumstance where there is extensive vulvar inflammation the labia majora, it may exhibit certain degree of agglutination. Rectal examination confirms the presence of a normal infantile uterus. 


\begin{tabular}{|c|c|c|c|c|c|}
\hline SN. Case & Year/Month & Age of child & $\begin{array}{c}\text { Socioeconomic } \\
\text { Status }\end{array}$ & Treatment & $\begin{array}{c}\text { Type of } \\
\text { Anaesthesia }\end{array}$ \\
\hline 1. SS & 2008 May & 5 year 6 months & Middle & $\begin{array}{l}\text { Adhesion was separated by } \\
\text { lubricated probe with } \\
\text { with quick firm pressure }\end{array}$ & Ketalar IM \\
\hline 2. KY & 2008 Sept. & 5 years 3 months & Middle & As above (as SN 1) & Ketalar IM \\
\hline 3. CS & 2008 Dec. & 4 years 2 months & Middle & As above (as SN 1) & Ketalar IM \\
\hline 4. AA & 2009 Sept. & 3 years 2 months & Low & $\begin{array}{l}\text { Lubricated probe } \\
\text { with xylocaine }\end{array}$ & Ketalar IM \\
\hline 5. VB & 2009 Dec. & 3 years 6 months & Low & As above (as SN 4 ) & Ketalar IM \\
\hline 6. LK & 2010 Sept. & 4 years 1 months & Low & $\begin{array}{c}\text { Firm pressure by lubricated } \\
\text { probe with xylocaine }\end{array}$ & Ketalar IM \\
\hline 7. UD & 2011 Nov. & 4 years 3 months & Low & Same as SN 6 & Ketalar IM \\
\hline 8. $\mathrm{HH}$ & 2012 Jan. & 3 years 9 months & Low & Same as SN 6 & Not necessary \\
\hline 9. NA & 2012 Feb. & 2 years 4 months & Middle & Same as SN 6 & Not necessary \\
\hline 10. US & 2012 May & 3 years 6 months & Low & Same as SN 6 & Not necessary \\
\hline
\end{tabular}

Table I : Showing the patient profile and the type of treatment was offered

\begin{tabular}{|c|c|c|c|}
\hline SN. Case & $\mathbf{3}$ months follow up & $\mathbf{6}$ months follow up & $\mathbf{1}$ year months follow up \\
\hline 1.SS & No recurrence & No recurrence & Did not come \\
\hline 2. KY & No recurrence & No recurrence & No recurrence \\
\hline 3. CS & No recurrence & No recurrence & Lost to follow up \\
\hline R. $\mathrm{AA}$ & $\begin{array}{c}\text { Recurrence }+ \\
\text { Procedure repeated }\end{array}$ & Lost to follow up & No recurrence \\
\hline 5. VB & No recurrence & No recurrence & Lost to follow up \\
\hline 6. LK & No recurrence & Lost to follow up & Lost to follow up \\
\hline 7. UD & $\begin{array}{c}\text { Recurrence } \\
\text { Procedure repeated }\end{array}$ & No recurrence & No recurrence \\
\hline 8. HH & No recurrence & No recurrence & No recurrence \\
\hline 9. NA & No recurrence & Pending & \\
\hline 10. US & \multicolumn{2}{|l}{} &
\end{tabular}

Table II : Showing result of follow up

\begin{tabular}{|l|c|c|c|c|c|c|c|c|}
\hline & $\mathbf{N}$ & Range & Minimum & Maximum & \multicolumn{2}{|c|}{ Mean } & Std. Dev. & Variance \\
\cline { 2 - 8 } & Statistics & Statistics & Statistics & Statistics & Statistics & Std. Error & Statistics & Statistics \\
\hline $\begin{array}{l}\text { Age of the subjects } \\
\text { Valid N (Listwise) }\end{array}$ & 10 & 3.20 & 2.40 & 5.60 & 4.0200 & 0.29657 & 0.93785 & 0.880 \\
\hline
\end{tabular}

Table III: Statistical analysis of the result 


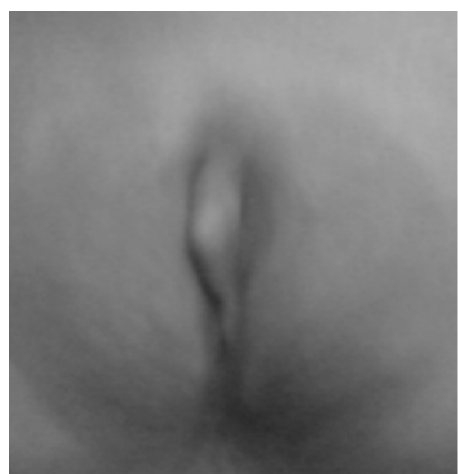

Figure 1: Showing typical labial adhesion with mid line raphe

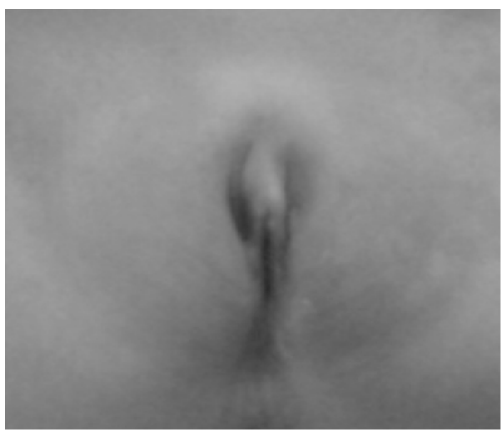

Figure 2: Showing labia minora after separation by lubricated probe

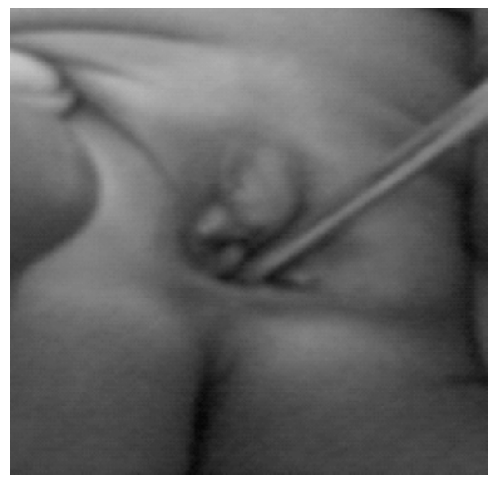

Figure 3: Showing the probe in situ after separation

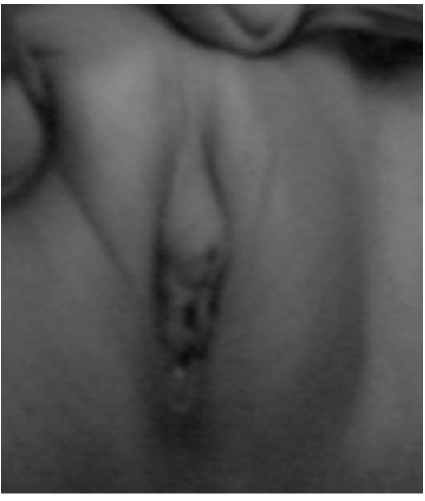

Figure 4: Follow up after 3 months
Labial agglutination should not be confused with labial fusion which is due to intra uterine, congenital or chronic, post nasal inflammation of vulva. In case of fusion simple incision has to be given but one should not confuse it with the virilised external genitalia. The gynecologist should be aware of the situation that labial agglutination is a self limiting condition which usually disappears at puberty when estrogen level in the blood rise. Agglutination encourages pocketing of urine irritation and infection. Labial adhesion may be treated as follows. Lubricated probe is inserted into the anterior opening through which the child passes urine and a quick firm pressure anteriorly readily separates the labia. Estrogen cream or petroleum jelly may be applied which would cornify the epithelium ${ }^{4}$. Repeated separation of labia may be required.

In a study of Gaumden DA et al 2008, 4 girls underwent surgical section and 20 girls received estrogen cream. Mean age was 22 months and 7 cases were five years of age ${ }^{5}$. Mayoglou et al 2009 treated 151 prepubertal girl mean age of 3 years (range between $0.25-8.75$ years) diagnosed to be labial adhesion with topical estrogen and betamethsone therapy was given $^{6}$. Patients treated primarily with topical conjugated estrogen as long as 2.2 months $^{6}$. Side effects of oestrogen include breast budding vaginal bleeding. Patients with labial agglutination frequently may encounter children for whom medical treatment has failed. Thick adhesion require manual separation, bacon et al. $2002^{7}$. Estrogen treatment has been tried with success with recurrent labial agglutination, Kumetz et al $2006^{8}$. Gaumdens DA et al. 2008 have used curved Halsted mosquito forceps to separate the adhesions.

The case treated by the authors are described as follows. None of them received topical estrogen cream. In this series we have tried surgical separation of the labia with no. 2 Hegars dilator ( $2 \mathrm{~mm}$ )and application of vaginal cream (antifungal, antibiotic and with steroid) for 4 weeks. The mean age of the subjects was 4.02 years with a standard deviation of 0.93 and range 3.2 to 2.4. The follow up were carried out for 12 months from the date of procedure.

All parents followed up regularly with their kids on first visit after 3 months. Out of 10 children 2 were found to have recurrent adhesions and the procedure was repeated. On second visit after 6 months from the primary procedure one child with repeat procedure did not show up and one without recurrence at first visit did not come up. On $3^{\text {rd }}$ visit after completion of 1 year $50 \%$ patients reported without any recurrence and rest could not report to us despite repeated reminder over telephone (poor compliance).

\section{CONCLUSION}

This benign disorder can be treated by any physician, gynaecologist provided they are aware of this condition. It is fairly simple to insert a lubricated probe and put quick pressure 
to separate adhesions. The psychological impact of the patient and her parent and necessary speed suggests that surgical treatment is the method of choice. Estrogen cream was not necessary in our series. Although larger sample size and long term follow up is needed to further confirm our inference.

\section{ACKNOWLEDGMENT}

We thank Dr. S. K. Kanodia, Managing Director, Nepalgunj Medical College, Kohalpur for permission to publish this article.

\section{REFERENCES}

1. Altchek A. Labial Adhesion. Pediatric Clin. North Am. 1981;28(2): 407-8.

2. Huffman JW, Dewhurst CJ, Capraro VJ. The gynecology of childhood and adolescence. WB-saunders company 1981;2: 1057.

3. Dominique Hamel-teillac, vulvo vaginal disorders, Sultan C (ed): Pediatric and Adolescent Gynaecology. Evidence based clinical practice. Endocr. Dev. Basel, Karger 2004;7:39-5.

4. Aribasgrg A. Topical oestrogen therapy for labial adhesions in children. Br J obstet Gynaecol.1975;82(5):424-5.

5. Gaumdens DA, Moh- Ellon N, Fiogbe M et al. Labial fusion in the pediatric surgery department of Yopougon university hospital (cote D voire) 108 cases .santa 2008;18 (1):35-8.

6. Myoglou L, Dulabon L, Martin A et al. success of treatment modalities for labial fusion. A retrospective evaluation of topical and surgical treatments. J. Pediatr. Adolesc. Gynecol. 2009;22(4): 247-50.

7. Bacon JL. Prepubertal labial adhesion, evaluation of referral population. Am. J. Obstet. Gynecol. 2002;187(2):327-31.

8. Kumetz LM, Quint EH, Fissehe S. Estrogen treatment success in recurrent and persistent labial agglutination. J Pediatr. Adolsc. Gynecol. 2006;19(6):381-4.

9. Caparo VJ. Adhesion of labia minor, a study of 50 patients. Obstet Gynaecol 1972;39(1):65-9.

10. Christensen EH, Oster J, Adhesions of labia minora (synechia vulvae) in childhood. A review and report of fourteen cases. Act pediatr. scand. 1971;60:709-15. 